\title{
Crank-Nicholson difference scheme for the system of nonlinear parabolic equations observing epidemic models with general nonlinear incidence rate
}

Evren Hincal $^{1}$, Bilgen Kaymakamzade ${ }^{1}$, and A. Ashyralyev ${ }^{1}$

${ }^{1}$ Near East University

April 27, 2020

\begin{abstract}
Crank-Nicholson difference scheme for the system of nonlinear parabolic equations observing epidemic models with general nonlinear incidence rate is investigated. The theorem on the existence and uniqueness of a bounded solution of Crank- Nicholson difference scheme uniformly with respect to time step is established. Applications of the theoretical results are presented for the four systems of one and multidimensio
\end{abstract}

\section{Hosted file}

ABE.pdf available at https://authorea.com/users/315201/articles/445565-crank-nicholson-differencescheme-for-the-system-of-nonlinear-parabolic-equations-observing-epidemic-models-with-generalnonlinear-incidence-rate 